\title{
Novel germline variant of TMEM127 gene in a patient with familial pheochromocytoma
}

\author{
Kohei Saitoh1, Takako Yonemoto1,2, Takeshi Usui2, Kazuhiro Takekoshi³, \\ Makoto Suzuki4, Yoshiharu Nakashima5, Koji Yoshimura5, Rieko Kosugi', \\ Tatsuo Ogawa' and Tatsuhide Inoue ${ }^{1}$ \\ Departments of ${ }^{1}$ Diabetes and Endocrinology and ${ }^{2}$ Medical Genetics, Shizuoka General Hospital, \\ Shizuoka, Japan, ${ }^{3}$ Division of Sports Science, Faculty of Medicine, University of Tsukuba, Tsukuba, Japan, \\ Departments of 4Pathology and 5Urology, Shizuoka General Hospital, Shizuoka, Japan
}

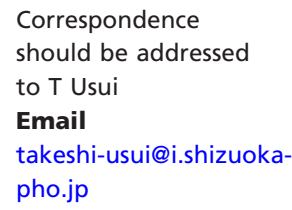

\section{Summary}

Pheochromocytomas (PCCs) and paragangliomas (PGLs) are rare tumours with a heterogeneous genetic background. Up to $40 \%$ of apparently sporadic PCC/PGL cases carry 1 of the 12 gene germline mutations conferring genetic susceptibility to PCC/PGL. Although the precise mechanisms are unclear, TMEM127 is one of the rare responsible genes for PCC/PGL. Here we report the case of a patient with familial PCC having a novel TMEM127 variant (c.119C > T, p.S40F). In silico prediction analysis to evaluate the functional significance of this variant suggested that it is a disease-causing variant. A PCC on the left side was considered to be the dominant lesion, and unilateral adrenalectomy was performed. The histopathologic findings were consistent with benign PCC. A loss of heterogeneity of the TMEM127 variant was detected in the surgically removed tumour.

\section{Learning points:}

- c.119C > T (p.S40F) is a novel TMEM127 variant that can cause pheochromocytoma.

- The tumour showed loss of heterozygosity of this TMEM127 variant.

- The clinical phenotype of this mutation is putative bilateral pheochromocytoma in the 4th decade.

- Unilateral adrenalectomy may be performed as the initial surgery in such cases.

\section{Background}

Pheochromocytoma (PCC) is a rare neoplasm that derives from the chromaffin cells of the adrenal medulla and produces and secretes catecholamines. Tumours that develop from the sympathetic ganglia are referred to as paragangliomas (PGLs). Genetic alterations are reportedly responsible for approximately $10 \%$ of all PCCs. A recent study, however, revealed that up to $40 \%$ of PCC/PGL patients carry a germline mutation in susceptibility genes such as RET, SDHA, SDHB, SDHC, SDHD, VHL,
NF1, TMEM127 and MAX (1). Therefore, the European Society of Endocrinology as well as the Endocrine Society recommend that genetic testing be considered for all patients with PCC/PGL, especially in cases with a positive family history; syndromic features; and multifocal, bilateral or metastatic disease $(2,3)$. The TMEM127 gene was recently identified as a new PCC susceptibility gene $(4,5,6,7,8,9)$. Only two independent Japanese families have been reported to have mutation in TMEM127 (10). 
Here we report a case of PCC in which a novel germline variant was detected in the TMEM 127 gene.

\section{Case presentation}

A 42-year-old man (weight $60 \mathrm{~kg}$, height $160 \mathrm{~cm}$ ) was referred to our hospital for further examination of a left adrenal mass incidentally discovered by ultrasonography during a routine physical check-up. He had never been diagnosed with hypertension, but on admission his blood pressure was $141 / 89 \mathrm{mmHg}$ with a regular pulse (76/min). He had no abnormal physical findings. His father underwent a unilateral adrenalectomy due to PCC at the age of 65 , and was being evaluated for residual or contralateral adrenal PCC.

\section{Investigation}

Laboratory tests revealed an adrenaline-dominant increase in the plasma and urinary catecholamine concentrations and their metabolites as follows: adrenaline $522 \mathrm{pg} / \mathrm{mL} \quad(<100 \mathrm{pg} / \mathrm{mL})$, noradrenaline $215 \mathrm{pg} / \mathrm{mL}$ (100-450 pg/mL), dopamine $8 \mathrm{pg} / \mathrm{mL}(<20 \mathrm{pg} /$ $\mathrm{mL}$ ), urinary metanephrine $3.61 \mathrm{mg} /$ day (0.04-0.19), and urinary normetanephrine $0.40 \mathrm{mg} /$ day $(0.09-0.33)$. Abdominal computed tomography (CT) revealed a left adrenal mass approximately $6 \mathrm{~cm} \times 4 \mathrm{~cm}$ in size (Fig. $1 \mathrm{~A}$ and $\mathrm{B}$ ). In $\mathrm{T} 2$-weighted magnetic resonance imaging (MRI) and diffusion-weighted images (DWI), the tumour exhibited relatively strong high signal intensity, and a cystic region was observed inside the tumour (Fig. 1C and D). 123I-Metaiodobenzylguanidine (MIBG) scintigraphy revealed positive uptake not only in the region corresponding to the left adrenal mass lesion, but also on the right adrenal gland, which did not appear abnormal by either CT or MRI (Fig. 2). Based on both his family history and putative bilateral PCC-based ${ }^{123}$ I-MIBG imaging studies, genetic alterations were suspected. A genetic analysis was performed for RET, VHL, SDHB, SDHD, MAX and TMEM127 under the patient's informed consent. A novel missense variant (c.119C > T, p.S40F) was identified in the TMEM127 gene (Fig. 3). All three in silico analyses (Mutation Taster, SIFT, and PolyPhen-2) predicted that this variant would produce a functional alteration.

\section{Treatment}

Although bilateral PCC was suspected, laparoscopic unilateral adrenalectomy of the left adrenal gland, which was thought to be the dominant side, was performed.

\section{Outcome and follow-up}

After surgery, his blood pressure normalized and the plasma and urinary catecholamine concentrations and their metabolites were within the normal range (plasma adrenaline $<5 \mathrm{pg} / \mathrm{mL}$, plasma noradrenaline $130 \mathrm{pg} /$ $\mathrm{mL}$, plasma dopamine $<5 \mathrm{pg} / \mathrm{mL}$, urinary metanephrine $0.1 \mathrm{mg} /$ day and normetanephrine $0.23 \mathrm{mg} /$ day). He has been well without recurrence for 1 year since the surgery.
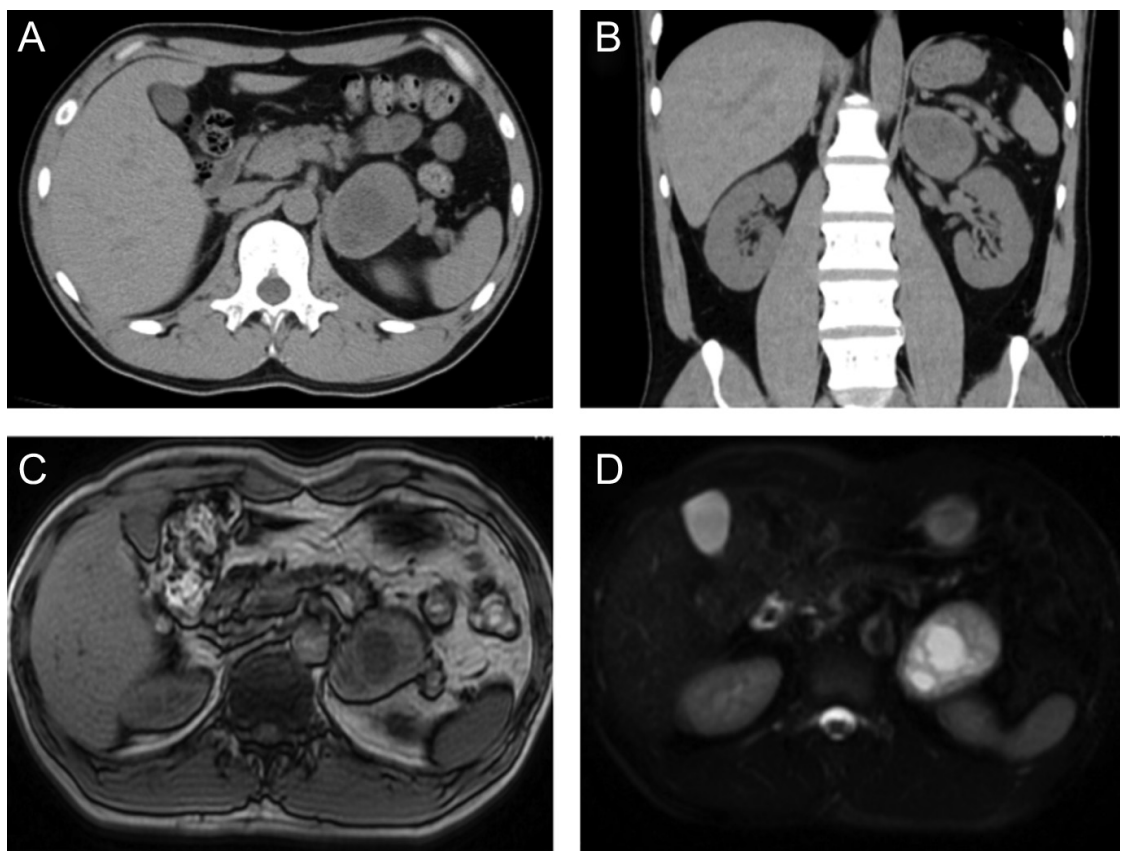

Figure 1

Imaging analysis of the adrenal mass. A coronal section (A) and sagittal section (B) on CT showed a mass with heterogeneous intensity in the left adrenal gland. T1-weighted (C) and T2-weighted (D) MRI. The left adrenal mass showed high signal intensity in T2-weighted MRI. 

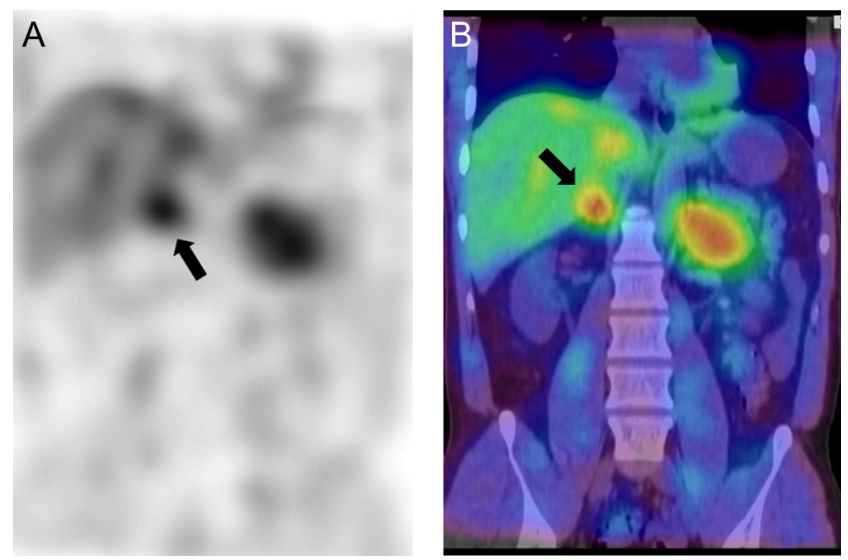

Figure 2

123I-MIBG imaging (A) and SPECT imaging (B) of the adrenal masses. In addition to the left adrenal mass, significant ${ }^{123}$ |-MIBG uptake was observed in the right adrenal gland (arrows).

The weight of the left glands with the mass was $89.5 \mathrm{~g}$ $(6.2 \times 4.0 \times 2.6 \mathrm{~cm})$. Histologic findings confirmed the diagnosis of PCC and the PCC of the adrenal gland scaled score (PASS score) was 2, suggesting a tumour with low likelihood of malignancy (Fig. 3).

Loss of heterozygosity (LOH) of the TMEM127 variant was confirmed by sequencing analysis of the surgically removed tumour, suggesting the functional significance of this variant (Fig. 4 middle panel). Although hereditary PCC in the father of this patient was suspected, he was not willing to undergo genetic testing for TMEM127.
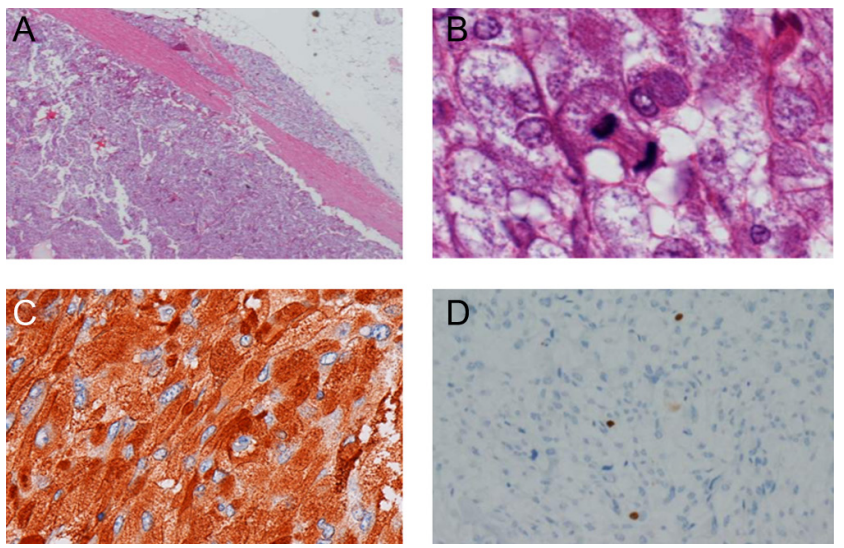

Figure 3

Histopathologic findings of the surgically removed left adrenal tumour. The lower magnification (A), and higher magnification (B) of haematoxylin and eosin stain. (C) Immunohistochemistry for chromogranin A: The brown staining indicates expression of chromogranin A in the tumour cells. Ki67 labelling index was low (approximately 1\%) (D).
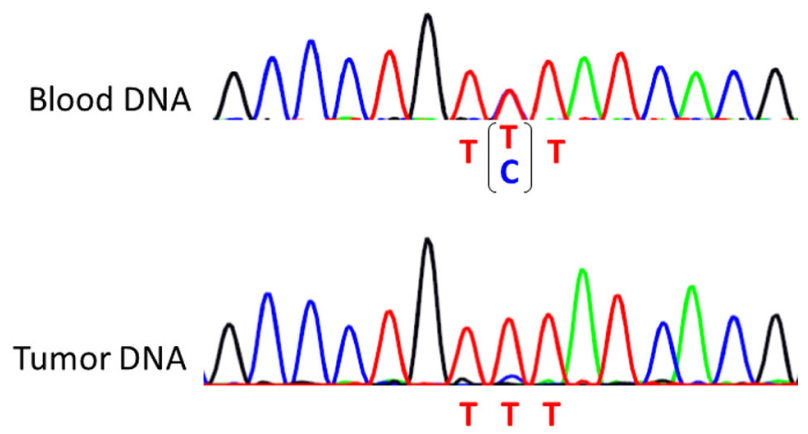

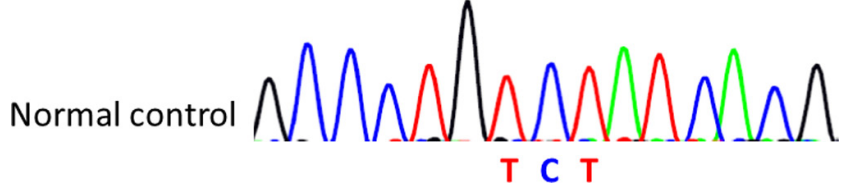

Figure 4

An electrophenogram around codon 40 in the TMEM127 gene in the peripheral blood DNA of the patient (upper panel), in the surgically removed tumour tissue (middle panel), and a normal control (lower panel). The peripheral blood DNA of the patient showed c.119C $>$ T in heterozygosity. The tumour tissue DNA showed loss of the wild-type $C$ allele, indicating $\mathrm{LOH}$.

\section{Discussion}

TMEM127 is a negative regulator of mammalian target of rapamycin effector proteins, which promote cell growth and protein translation. TMEM127 protein interacts with several effector proteins of receptor kinase intracellular signalling pathways, and eventually acts as tumour suppressor protein (4). As TMEM127 acts as tumour suppressor, a second hit is necessary to develop the tumourigenesis in TMEM127 mutated PCC/PGL patients. In the present case, we identified a novel TMEM127 gene missense variant (c.119C > T, p.S40F). This variant was classified as likely pathogenic by ACMG guideline (11). Although genetic heredity was not confirmed due to the father's unwillingness to undergo genetic testing, in silico analysis and the demonstration of the second hit of this variant (i.e., LOH) strongly suggest that this variant affects the function of the TMEM127 protein.

The present case suggested two important clinical issues regarding the characteristics and management of PCC with a TMEM127 mutation. First, in addition to reporting a novel pathogenic variant of TMEM127, we describe a rare case of TMEM127-related familial PCC. This is the third Japanese family of TMEM127-mediated PCC with distinct variant from the previous two families (10). In a recent study of 990 individuals with PCC/PGL, screening identified potentially pathogenic TMEM127 mutations in only 20 patients (2\%) presenting with 
PCC, 5 of whom had a family history of PCC (12). A previous study revealed that family history is confirmed in approximately $15 \%$ of cases (12). In another study of 151 individuals from a 6-generation family carrying a TMEM127 germline mutation, the median age was 43 years, and the cumulative penetrance rate was $0 \%$ at $0-20$ years, $3 \%$ at $21-30$ years, $15 \%$ at $31-40$ years, $24 \%$ at $41-50$ years and $32 \%$ at $51-65$ years (13). These studies suggest that the penetrance of TMEM127-related PCC/PGL is relatively low. The present case may provide additional information on the penetrance of TMEM127-related PCC/ PGL. According to the recommendations of the Endocrine Society, mutation carriers should undergo annual clinical surveillance (2). The proband in the present case has two sons, ages 7 and 9 years, and thus we recommend careful genetic counselling for their health management.

Second, unilateral adrenalectomy may be selected as the initial surgery in such cases. TMEM127-mediated PCC is bilateral in 30\% of cases (12). In the present case, although CT and MRI did not support bilateral PCC, findings from the 123I-MIBG study suggested bilateral lesions. Therefore, we diagnosed the patient with bilateral PCC with a TMEM127 variant. In the present case, 1 year after unilateral adrenalectomy, the patient's blood pressure was normal and plasma and urinary catecholamine concentrations and their metabolites levels were in the normal range. Although uptake to right adrenal gland could have been a false positive finding, we speculate that the right adrenal PCC was too small to detect on CT or MRI, and to reveal clinical symptoms and biochemical alterations. This lesion, however, should continue to be carefully observed.

In conclusion, we report a case of familial and possibly bilateral PCC with a novel TMEM127 variant, and unilateral adrenalectomy for the dominant tumour provided clinical and biochemical remission of PCC for at least 1 year.

\section{Declaration of interest}

The authors declare that there is no conflict of interest that could be perceived as prejudicing the impartiality of the research reported.

\section{Funding}

This research did not receive any specific grants from any funding agency in the public, commercial or not-for-profit sector.

\section{Patient consent}

Written informed consent to publish these findings was obtained from the patient.
Author contribution statement

$\mathrm{K}$ Saioh and $\mathrm{T}$ Yonemoto evaluated the patients. $\mathrm{K}$ Takekoshi performed genetic analysis. T Usui reviewed and performed further investigations including $\mathrm{LOH}$ analysis on the patient. Treatment decisions were made by all of the authors. Y Nakashima and K Yoshimura performed the surgery. M Suzuki performed the pathological analyses. K Saitoh prepared the initial draft of the manuscript. All authors contributed equally to writing the draft and preparing the final manuscript.

\section{References}

1 Favier J, Amar L \& Gimenez-Roqueplo AP 2015 Paraganglioma and phaeochromocytoma: from genetics to personalized medicine. Nature Reviews Endocrinology 11 101-111. (doi:10.1038/nrendo.2014.188)

2 Lenders JW, Duh QY, Eisenhofer G, Gimenez-Roqueplo AP, Grebe SK, Murad MH, Naruse M, Pacak K \& Young WF Jr 2014 Pheochromocytoma and paraganglioma: an endocrine society clinical practice guideline. Journal of Clinical Endocrinology and Metabolism 99 1915-1942. (doi:10.1210/jc.2014-1498)

3 Plouin PF, Amar L, Dekkers OM, Fassnacht M, Gimenez-Roqueplo AP, Lenders JW, Lussey-Lepoutre C \& Steichen O 2016 European Society of Endocrinology Clinical Practice Guideline for long-term follow-up of patients operated on for a phaeochromocytoma or a paraganglioma. European Journal of Endocrinology 174 G1-G10. (doi:10.1530/EJE-16-0033)

4 Qin Y, Yao L, King EE, Buddavarapu K, Lenci RE, Chocron ES, Lechleiter JD, Sass M, Aronin N, Schiavi F, et al. 2010 Germline mutations in TMEM127 confer susceptibility to pheochromocytoma. Nature Genetics 42 229-233. (doi:10.1038/ng.533)

5 Elston MS, Meyer-Rochow GY, Prosser D, Love DR \& Conaglen JV 2013 Novel mutation in the TMEM127 gene associated with phaeochromocytoma. Internal Medicine Journal 43 449-451. (doi:10.1111/imj.12088)

6 Burnichon N, Lepoutre-Lussey C, Laffaire J, Gadessaud N, Molinié V, Hernigou A, Plouin PF, Jeunemaitre X, Favier J \& GimenezRoqueplo AP 2011 A novel TMEM127 mutation in a patient with familial bilateral pheochromocytoma. European Journal of Endocrinology 164 141-145. (doi:10.1530/EJE-10-0758)

7 Abermil N, Guillaud-Bataille M, Burnichon N, Venisse A, Manivet P, Guignat L, Drui D, Chupin M, Josseaume C \& Affres H 2012 TMEM127 screening in a large cohort of patients with pheochromocytoma and/or paraganglioma. Journal of Clinical Endocrinology and Metabolism 97 E805-E809. (doi:10.1210/jc.20113360)

8 Patócs A, Lendvai NK, Butz H, Liko I, Sapi Z, Szucs N, Toth G, Grolmusz VK, Igaz P, Toth M, et al. 2016 Novel SDHB and TMEM127 mutations in patients with pheochromocytoma/paraganglioma syndrome. Pathology and Oncology Research 22 673-679. (doi:10.1007/ s12253-016-0050-0)

9 King EE, Qin Y, Toledo RA, Luo A, Ball E, Faucz FR, Janeway KA, Stratakis CA, Tomlinson GE \& Dahia PL 2015 Integrity of the pheochromocytoma susceptibility TMEM127 gene in patients with pediatric malignancies. Endocrine-Related Cancer 22 L5-L7. (doi:10.1530/ERC-15-0101)

10 Takeichi N, Midorikawa S, Watanabe A, Naing BT, Tamura H, Wakakuri-Kano T, Ishizaki A, Sugihara H, Nissato S, Saito Y, et al. 2012 Identical germline mutations in the TMEM127 gene in two unrelated Japanese patients with bilateral pheochromocytoma. Clinical Endocrinology 77 707-714. (doi:10.1111/j.13652265.2012.04421.x)

11 Richards S, Aziz N, Bale S, Bick D, Das S, Gastier-Foster J, Grody WW, Hegde M, Lyon E, Spector E, et al. 2015 Standards and guidelines for the interpretation of sequence variants: a joint consensus recommendation of the American College of Medical Genetics and 
Genomics and the Association for Molecular Pathology. Genetics in Medicine 17 405-424. (doi:10.1038/gim.2015.30)

12 Yao L, Schiavi F, Cascon A, Qin Y, Inglada-Perez L, King EE, Toledo RA, Ercolino T, Rapizzi E, Ricketts CJ, et al. 2010 Spectrum and prevalence of FP/TMEM127 gene mutations in pheochromocytomas and paragangliomas. JAMA 304 2611-2619. (doi:10.1001/jama.2010.1830)
13 Toledo SP, Lourenco DM Jr, Sekiya T, Lucon AM, Baena ME, Castro CC, Bortolotto LA, Zerbini MC, Siqueira SA, Toledo RA, et al. 2015 Penetrance and clinical features of pheochromocytoma in a sixgeneration family carrying a germline TMEM127 mutation. Journal of Clinical Endocrinology and Metabolism 100 E308-E318. (doi:10.1210/ jc.2014-2473)

Received in final form 21 February 2017

Accepted 2 March 2017 